\title{
Loss of NPC1 function in a patient with a co-inherited novel insulin receptor mutation does not grossly modify the severity of the associated insulin resistance
}

\author{
J. Kirk • K. M. Porter • V. Parker • I. Barroso • \\ S. O'Rahilly $\cdot$ C. Hendriksz $\cdot$ R. K. Semple
}

Received: 20 January 2010 /Revised: 31 March 2010 /Accepted: 12 April 2010 /Published online: 3 June 2010

(C) The Author(s) 2010

\begin{abstract}
In Npcl null mice, a model for Niemann Pick Disease Type $\mathrm{C} 1$, it has been reported that hepatocyte insulin receptor function is significantly impaired, consistent with growing evidence that membrane fluidity and microdomain structure have an important role in insulin signal transduction. However, whether insulin receptor function is also compromised in human Niemann Pick disease Type $\mathrm{C} 1$ is unclear. We now report a girl who developed progressive dementia, ataxia and opthalmoplegia from 9 years old, followed by severe
\end{abstract}

Communicated by: Ed Wraith

References to electronic databases: Niemann Pick Disease Type C (OMIM\#257220)

Type A Insulin Resistance (OMIM\#610549)

NPC1 (GenBank NM 000271)

INSR (GenBank NM_000208)

Competing interest: None declared.

J. Kirk

Department of Endocrinology, Birmingham Children's Hospital,

Steelhouse Lane,

Birmingham B4 6NH, United Kingdom

K. M. Porter · V. Parker · S. O'Rahilly $\cdot$ R. K. Semple $(\bowtie)$

Metabolic Research Laboratories, Institute of Metabolic Science,

Addenbrooke's Hospital, University of Cambridge,

Cambridge CB2 0QQ, UK

e-mail: rks16@cam.ac.uk

I. Barroso

The Wellcome Trust Sanger Institute,

Wellcome Trust Genome Campus,

Hinxton,

Cambridge CB10 1SA, United Kingdom

C. Hendriksz

Clinical Inherited Metabolic Disorders,

Birmingham Children's Hospital,

Steelhouse Lane,

Birmingham B4 6NH, United Kingdom acanthosis nigricans, hirsutism and acne at 11 years old. She was diagnosed with Niemann Pick Disease type C1 (OMIM\#257220) based on positive filipin staining and reduced cholesterol-esterifying activity in dermal fibroblasts, and homozygosity for the p.Ile1061Thr NPCl mutation. Further analysis revealed her also to be heterozygous for a novel trinucleotide deletion (c.3659+1_3659+3delGTG) at the end of exon 20 of INSR, encoding the insulin receptor, leading to deletion of Trp1193 in the intracellular tyrosine kinase domain. INSR mRNA and protein levels were normal in dermal fibroblasts, consistent with a primary signal transduction defect in the mutant receptor. Although the proband was significantly more insulin resistant than her father, who carried the INSR mutation but was only heterozygous for the $\mathrm{NPCl}$ variant, their respective degrees of IR were very similar to those previously reported in a father-daughter pair with the closely related p.Trp1193Leu INSR mutation. This suggests that loss of NPC1 function, with attendant changes in membrane cholesterol composition, does not significantly modify the IR phenotype, even in the context of severely impaired INSR function.

\section{Abbreviations \\ IR Insulin resistance}

\section{Introduction}

Insulin resistance (IR) and its clinical sequelae, including type 2 diabetes, atherosclerosis and polycystic ovary syndrome, are now at pandemic levels(Zimmet et al. 2001), and yet the precise molecular pathogenesis of defective insulin action in the prevalent form of the condition remains unclear. One strategy for gaining 
mechanistic insights into insulin action in vivo is to identify and physiologically characterise naturally-occurring genetic defects resulting in extreme forms of IR (O'Rahilly 2007). The commonest Mendelian forms of primary IR are accounted for by mutations in the gene encoding the insulin receptor, INSR. At the most severe end of the spectrum, biallelic mutations lead to autosomal recessive Donohue and Rabson Mendenhall syndromes (Taylor et al. 1992). However heterozygous mutations in the tyrosine kinase domain of the insulin receptor are more common, and produce autosomal dominant severe IR that presents peripubertally in females with acanthosis nigricans, hyperandrogenism and ovulatory dysfunction, often with hyperglycaemia (Musso et al. 2004). More than 100 loss-of-function alleles have now been described, and a comprehensive mechanistic classification of the defects has been established (Taylor et al. 1992).

However, insulin action depends upon more than just integrity of each of the components of the signalling pathway: correct spatial organisation of the insulin receptor and its downstream signal transducers is also critical, and it is now well established that insulin receptors are clustered in specific microdomains of the plasma membrane, or lipid rafts, defined in part by local membrane lipid composition (Yaqoob 2009). A corollary of this is that pathological alterations in membrane lipid composition and fluidity may perturb insulin receptor function, and may contribute to prevalent IR. Indeed, impaired insulin action has been described in Gaucher disease, attributed to pathological accumulation of GM3 gangliosides in the plasma membrane (Langeveld et al. 2008a, b). Recently cell autonomous IR has also been described in hepatocytes of $\mathrm{Balb} / \mathrm{C}$ mice with naturally occurring disruption of the $\mathrm{Npcl}$ gene due to an inserted retroposon, a genetic model of Niemann Pick disease type C1. In these mice, cholesterol accumulation in the plasma membrane perturbs membrane fluidity and impairs signalling by hepatic insulin receptors (Vainio et al. 2005), which would be expected to lead to systemic IR. However, whether this phenomenon is also operative in humans with $\mathrm{NPCl}$ defects is not known. We now describe a patient with Niemann Pick disease type $\mathrm{C} 1$ who co-inherited a novel heterozygous mutation in the tyrosine kinase domain of the insulin receptor. Her degree of IR was approximately commensurate with that previously reported in a patient with a mutation of the same amino acid residue in the insulin receptor, suggesting that any additional effect of the $\mathrm{NPCl}$ defect on insulin receptor signalling is mild at most.

\section{Materials and methods}

NPC1 mutation detection, filipin staining and cholesterol esterification assays were undertaken by Dr M. Vanier at the Centre Hospitalier Lyon-Sud using previously pub- lished protocols (Chikh et al. 2004; Millat et al. 2005). Insulin, leptin, and adiponectin were assayed using customised autoDELFIA assays as previously described (Semple et al. 2006).

Genetic study of the insulin receptor gene was undertaken with full informed consent in line with procedures approved by the local research ethics committee in Cambridge, U.K. Genomic DNA was extracted from peripheral blood leukocytes before PCR amplification of all 22 exons of the INSR plus $50 \mathrm{bp}$ of flanking sequence at either end of the exons using 22 pairs of primers that had been designed in-house using ExonPrimer via the USC genome browser (http:// genome.ucsc.edu/) and checked for common polymorphisms using the NGRL Manchester program (http://ngrl.man.ac.uk/ SNPCheck/SNPCheck.html). The PCR products were purified using Agencourt ${ }^{\circledR}$ CleanSEQ ${ }^{\circledR}$ reagents (Agencourt Bioscience, Beverly, MA, USA) and sequenced in both directions using the BigDye ${ }^{\circledR}$ Terminator v3.1 Cycle Sequencing Kit (Applied Biosystems, PerkinElmer, Foster City, CA, USA) and an ABI 3730 DNA sequencer (Applied Biosystems). Sequence analysis was performed using Softgenetics $^{\circledR}$ Mutation Surveyor ${ }^{\mathrm{TM}}$ (State College, PA, USA).

Dermal fibroblasts were maintained in Dulbecco's Modification of Eagle's Medium supplemented with $10 \%$ foetal calf serum, $2 \mathrm{mmol} / \mathrm{l}$ glutamine and penicillin/ streptomycin (all from Sigma Aldrich, St Louis, MO). Cells were washed with phosphate-buffered saline before harvest. RNA was extracted from cells using the RNEasy kit (Qiagen) according to manufacturer's instructions, and $1 \mu \mathrm{g}$ of extracted, purified RNA was reverse transcribed in a total volume of $50 \mu \mathrm{l}$ using $400 \mathrm{ng}$ Random Primers, 400U Reverse Transcriptase and $0.5 \mathrm{mM}$ dNTPs (all from Promega, Madison, WI). cDNA was sequenced as described for genomic DNA but using cDNA as template.

INSR mRNA was quantified using custom designed probes and primers (Probe: 5' FAM-AGGCTGTGGTGCTGA TG-TAMRA-3'; F Primer: 5'-GCAGATCCGCATG TCCCTT-3'; R Primer: 5'-TGTTTTCCAGGTGCCCTC G-3'), Taqman Master Mix (Applied Biosystems) and an Applied Biosystems 7300 real-time PCR analyser. Results were normalised to expression of 36B4 for which custom designed probes and primers were used (Probe: 5' JOE-AGGCTGTGGTGCTGATG-TAMRA-3'; F Primer: 5'-GCAGATCCGCATGTCCCTT-3'; R Primer: 5'-TGTTTTCCAGGTGCCCTCG-3'). For each gene, a standard curve was generated and used to determine relative gene expression.

For protein studies, subconfluent fibroblasts were lysed on ice in $500 \mu \mathrm{l}$ of protein lysis buffer $(50 \mathrm{mM}$ Hepes, $150 \mathrm{mM} \mathrm{NaCl}, 30 \mathrm{mM} \mathrm{NaF}, 10 \mathrm{mM} \mathrm{Na} \mathrm{P}_{2} \mathrm{O}_{7}, 1 \mathrm{mM}$ $\mathrm{Na}_{2} \mathrm{VO}_{4}, 1 \%$ Triton X100, 10 mM EDTA, $0.5 \mathrm{mM}$ PMSF) before incubation on a rotary agitator platform for $30 \mathrm{~min}$ at $4^{\circ} \mathrm{C}$ and removal of cell debris by centrifugation at $12,000 \mathrm{~g}$ 
for $15 \mathrm{~min}$. The supernatant containing cellular protein was transferred to a fresh microfuge tube, quantified and stored at $-80^{\circ} \mathrm{C}$. Later, $400 \mu \mathrm{g}$ of each lysate was incubated for $3 \mathrm{~h}$ at $4^{\circ} \mathrm{C}$ with an insulin receptor-specific monoclonal antibody (83-14; a gift from Prof. Kenneth Siddle; Soos et al. 1989) in a solution made up to $1 \mathrm{ml}$ with immunoprecipitation buffer (50 mM Hepes, $150 \mathrm{mM} \mathrm{NaCl}, 30 \mathrm{mM}$ $\mathrm{NaF}, 10 \mathrm{mM} \mathrm{Na}{ }_{4} \mathrm{P}_{2} \mathrm{O}_{7}$ ), followed by addition of $50 \mu \mathrm{l}$ prewashed Protein A-agarose (Sigma Aldrich) and further incubation for $1 \mathrm{~h}$ at $4^{\circ} \mathrm{C}$. Beads were then washed using wash buffer (immunoprecipitation buffer plus $10 \mathrm{mM}$ EDTA, $0.2 \%$ Triton X100 and protease inhibitors; Roche) prior to washing and collection by centrifugation. Samples were re-suspended in $30 \mu \mathrm{l} 1.5 \times \mathrm{SDS}$ loading buffer (75 mM Tris-HCL pH6.8, 3\% w/v SDS, 15\% v/v glycerol, $0.00015 \% \mathrm{w} / \mathrm{v}$ bromophenol blue, $15 \mathrm{v} / \mathrm{v} \beta-\mathrm{ME})$ before western blotting.

Western blot analysis of $15 \mu \mathrm{l}$ of immunoprecipitate used an $8 \%$ reducing polyacrylamide gel, followed by transfer to an Immobilon-P transfer membrane (Millipore, Billerica, MA). The membrane was probed with anti-total Insulin Receptor $\beta$-chain antibody (SC-711; Santa Cruz Biotech,).

\section{Case History}

The female proband presented at 9 years old with slurred speech and mild gait unsteadiness, at which stage computed tomography of her brain was unremarkable. She was born at term at $2.76 \mathrm{~kg}$ to parents who were first cousins, and early development was unremarkable. At 11 years old, she developed acanthosis nigricans, widespread acne, hirsutism and deepening of her voice. She had not yet experienced menarche. Examination at 12 years old revealed a height of $159.8 \mathrm{~cm}$ (50th centile), weight $53.8 \mathrm{~kg}$ ( 75 th centile) and body mass index of $21 \mathrm{~kg} / \mathrm{m}^{2}$ (+0.9SD). MRI imaging at this stage showed increased signal intensity in the periventricular white matter creating a hazy appearance which, although often regarded as non-significant, we have frequently observed in patients with Niemann Pick type C1 disease (C. Hendriksz, unpublished observation). There was prominent axillary acanthosis nigricans, Ferriman Gallwey Grade 3 facial hirsutism, Tanner stage 4 pubic hair, stage 3 axillary hair and stage 3 breast development. There was mild cliteromegaly but otherwise unremarkable genitalia. Investigation showed elevated serum testosterone and androstenedione (at $4.8 \mathrm{nmol} / 1$ and $13.4 \mathrm{nmol} / 1$, respectively) with high levels of urinary androgen and cortisol metabolites, but no excess intermediates to suggest a biosynthetic defect. Her 17 hydroxyprogesterone was normal (2.9 nmol/1). Abdominal ultrasonography showed polycystic ovaries and a normal prepubertal uterus. Two gallstones and heterogeneously increased hepatic echotexture were incidentally noted. Oral glucose tolerance testing showed impaired glucose tolerance with severe hyperinsulinaemia (Table 1). A combined oral contraceptive preparation containing cyproterone acetate (Dianette), oxytetracycline and depilation were commenced and produced considerable improvement in both acne and hirsutism; however, metformin was not tolerated due to gastrointestinal side effects. Despite this, a further oral glucose tolerance test performed 2 years later showed normal glucose tolerance.

Neurological examination at 12 years old was reported to reveal myopathic facies with ptosis, some supranuclear impairment of upgaze, and somewhat nasal and dysarthric speech. There was a broad-based ataxic gait, pes cavus, increased lumbar lordosis, and mild proximal leg weakness with hyperreflexia. Blood chitotriosidase was elevated on two occasions. Muscle biopsy showed minor non-specific myopathic features, and moderate hypertrophy of type IIb fibres. Filipin staining of cultured skin fibroblasts showed massive accumulation of perinuclear vesicles, while cholesterol ester formation in lipoprotein deficient serum was grossly reduced at $30 \mathrm{pmol} / 4.5 \mathrm{hours} / \mathrm{mg}$ protein $(5 \mathrm{th}-95 \mathrm{th}$ centile for controls 550-5350). Sequencing of the NPC1

Table 1 Demographic and biochemical features of family members. Sex and BMI-specific normal ranges are indicated in parentheses for leptin

\begin{tabular}{llllllllll}
\hline $\begin{array}{l}\text { Family } \\
\text { member }\end{array}$ & Sex & $\begin{array}{l}\text { Age } \\
\text { (years })\end{array}$ & $\begin{array}{l}\text { B.M.I. } \\
\left(\mathrm{kg} / \mathrm{m}^{2}\right)\end{array}$ & $\begin{array}{l}\text { Fasting } \\
\text { glucose } \\
(\mathrm{mmol} / \mathrm{l})\end{array}$ & $\begin{array}{l}\text { Fasting } \\
\text { insulin } \\
(\mathrm{pmol} / \mathrm{l})\end{array}$ & $\begin{array}{l}120 \mathrm{~min} \\
\text { glucose }^{\mathrm{a}} \\
(\mathrm{mmol} / \mathrm{l})\end{array}$ & $\begin{array}{l}\text { Leptin } \\
(\mathrm{mcg} / \mathrm{l})\end{array}$ & $\begin{array}{l}\text { Adiponectin } \\
(\mathrm{mg} / \mathrm{l})\end{array}$ & $\begin{array}{l}\text { Serum lipid } \\
(\mathrm{mmol} / \mathrm{l})\end{array}$ \\
\hline II.15 & F & 70 & 24.3 & 4.7 & 73 & 6.5 & - & - & - \\
III.1 & F & 38 & 26.9 & 4.9 & 74 & 5.5 & - & - & - \\
III.2 & M & 40 & 25.6 & 4.9 & 349 & 7.1 & $7.1(1.5-13.0)$ & 3.9 & Tg 0.9 HDL-C 0.83 \\
IV.1 & F & 12 & 23.7 & 3.1 & 1096 & 10.0 & $21.8(2.4-24.4)$ & 10.6 & Tg 0.4 HDL-C 1.02 \\
IV.2 & M & 9 & 18.6 & 5.6 & 63 & 5.5 & - & - & - \\
Normal range & - & - & - & $3.5-5.5$ & $0-60$ & $<7.8$ & - & $\mathrm{b}$ & Tg $<2.2$ HDL-C $>0.9$ \\
\hline
\end{tabular}

${ }^{\text {a }}$ Refers to time after $75 \mathrm{~g}$ oral glucose load

${ }^{\mathrm{b}}$ In the context of severe insulin resistance, an adiponectin of $>7 \mathrm{mg} / \mathrm{l}$ has a $97 \%$ positive predictive value for insulin receptoropathy 


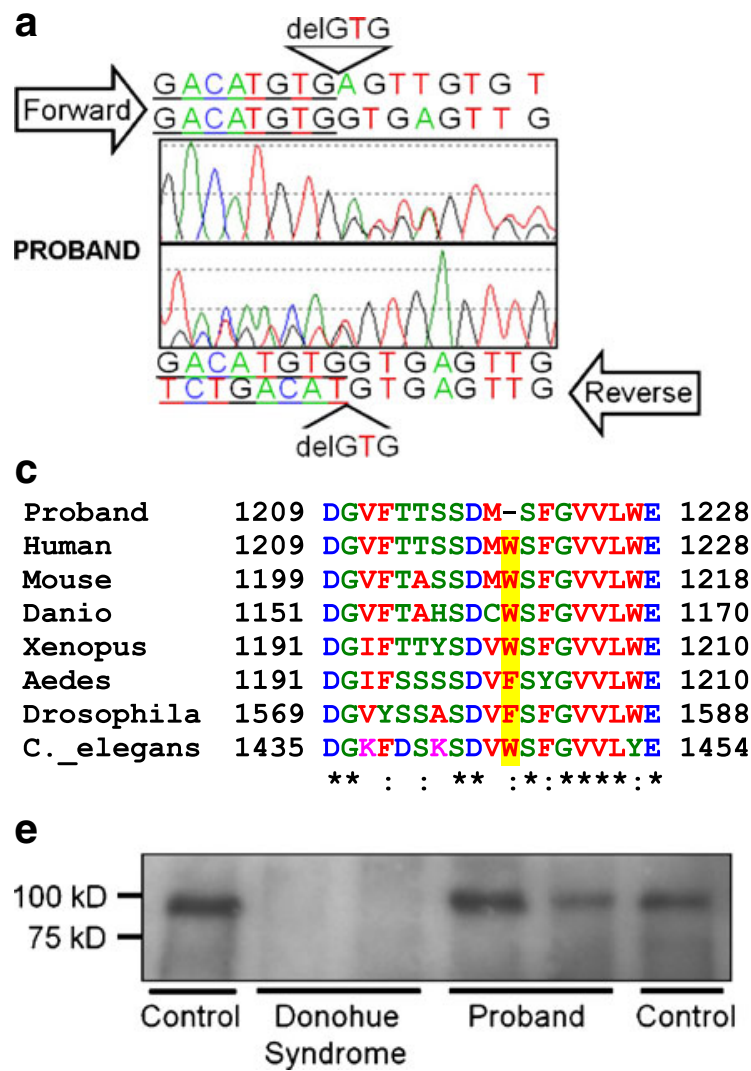

Fig. 1 The Proband has a heterozygous GTG deletion at the end of exon 20 of the INSR gene in genomic DNA (a), which is seen also in INSR cDNA (b). The nucleotide deletion causes deletion of Trp1220 (Trp1193 in the mature receptor), a strongly conserved residue (c) located in an alpha helix within the tyrosine kinase damin of the

gene (GenBank NM_000271) revealed homozygosity for the p.Ile1061Thr mutation, the commonest pathogenic mutation in Europids (Millat et al. 1999).

Further sequencing of genomic DNA revealed heterozygosity for the previously unreported deletion of one of a pair of trinucleotides around the end of exon 20 of the INSR

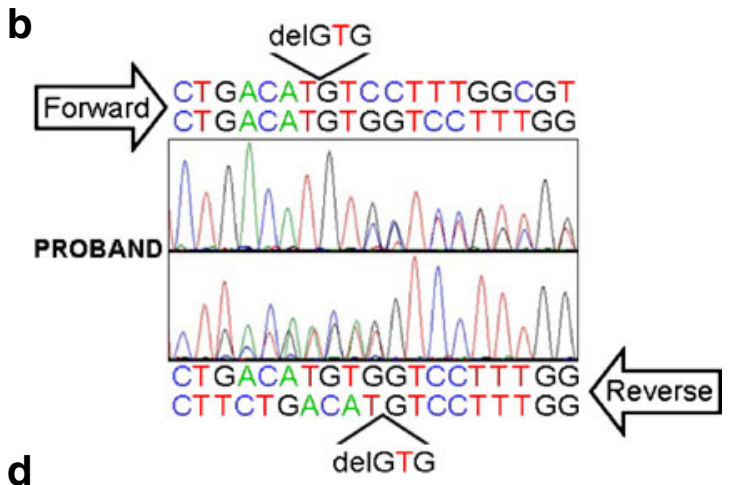

INSR mRNA Levels in Skin Fibroblasts

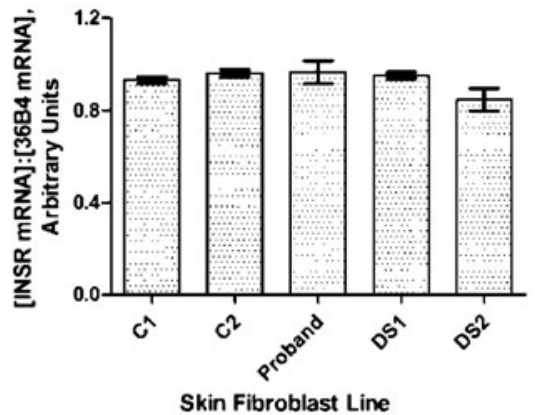

receptor. There was no detectable change in expression of the INSR in dermal fibroblasts from the proband as assessed by quantitative real time PCR (d) and immunoprecipitation/immunoblotting (e) for the insulin receptor beta subunit

gene (GenBank NM_000208; c.3659+1_3659+3delGTG) (Fig. 1a). Sequencing of cDNA from dermal fibroblasts confirmed heterozygous deletion of this trinuceotide also in the cDNA (Fig. 1b), leading to deletion of the highly conserved Tryptophan 1193 from the mature receptor (Fig. 1c). Quantitative real time PCR and immunoprecip-
Fig. 2 Family tree of the proband (arrowed) including $N P C 1$ and INSR genotype and clinical status. Black shading Niemann Pick Disease Type C1, hatched shading severe insulin resistance. Where genotypes are not given, they are unknown

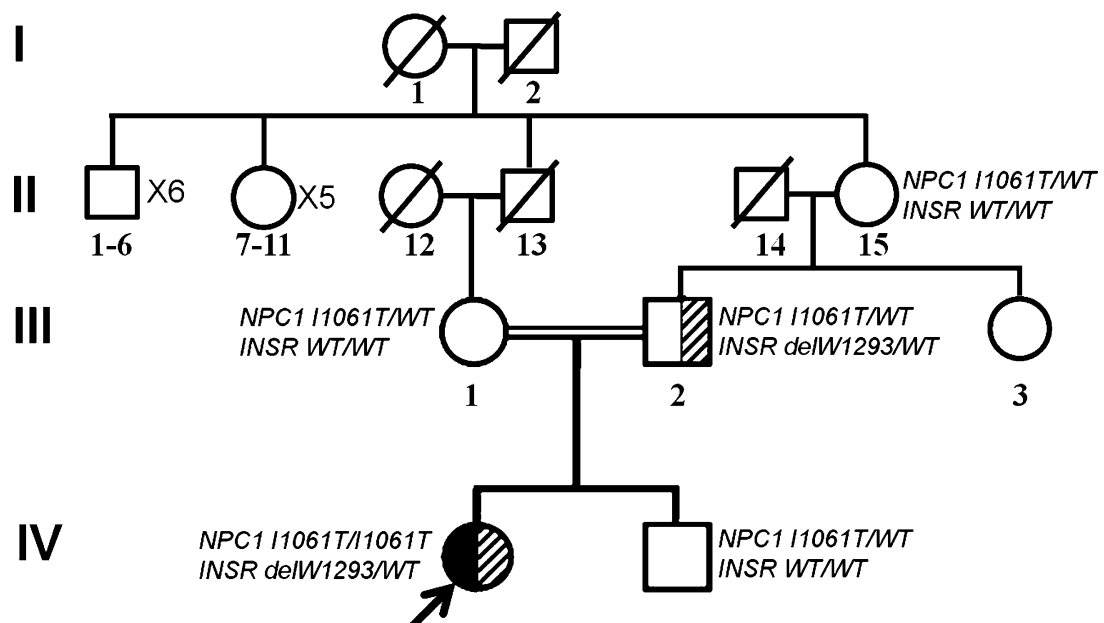


itation/immunoblotting showed no reduction in INSR expression in dermal fibroblasts from the proband compared to controls (Fig. 1d, e).

Fasting glucose and insulin were determined in the proband's parents and brother, each of whom were also genotyped for the INSR and NPC1 mutations found in the proband (Fig. 2). The father of the proband was a double heterozygote for the NPC1 and INSR mutations, while no other family member carried the INSR mutation. He was also severely IR, but markedly less so than the proband, as assessed by the level of fasting hyperinsulinemia. The proband's mother and 9-year-old brother were well. However, although the brother had normal levels of plasma insulin, he also had impaired fasting glycaemia using the American Diabetes Association International Society for Paediatric and Adolescent Diabetes guidelines.

\section{Discussion}

The single tryptophan deletion (delTrp1293) described here in the insulin receptor is novel, although a missense mutation changing the same tryptophan to leucine (Trp1293Leu) has previously been described and functionally characterised (Iwanishi et al. 1993). While the Trp1293Leu species was reported to show severely impaired processing and cell surface expression,levels of the mature beta subunit of the insulin receptor in dermal fibroblasts from the proband with the heterozygous delTrp1293 were, however, normal. This may be because the loss of function of the delTrp1293 receptor is accounted for purely by impaired signal transduction rather than loss of its cell surface expression. A caveat to this interpretation is, however, suggested by the observation in mice that loss of Npc1 function leads to upregulation of cell surface Insr expression (Vainio et al. 2005), which, if also operative in human dermal fibroblasts, may mask an additional effect of the novel delTrp1293 mutation on receptor processing. A large body of literature has established that missense mutations or deletions affecting the beta subunit of the insulin receptor characteristically exert dominant negative activity over co-expressed wild-type receptor. This is due to a requirement for activity of both constituent monomers in order for receptor autophosphorylation to occur in response to insulin (Odawara et al. 1989; Whittaker et al. 1990). A corollary of this is that, as long as processing and membrane residency time of the mutant receptor is normal, it is to be expected that only $25 \%$ of cell surface receptor dimmers will be functional. This most commonly leads to severe IR that presents around the time of puberty in girls, which may be precocious, as hyperandrogenism, oligomenorrhoea and acanthosis nigricans (Taylor et al. 1992).
There have been no reports of severe insulin resistance in Niemann Pick disease type $\mathrm{C} 1$, nor any cross-sectional studies of the range of insulin sensitivity in this condition to permit a judgement to made about the integrity of insulin receptor function. In this case, the independent defect in the insulin receptor, likely to reduce receptor function by around $75 \%$, is enough to cause severe IR on its own. However, it is also likely to sensitize the patient to "second hits" at the level of the receptor. For example, haploinsufficiency for the insulin receptor does not produce severe IR in slim patients, but produces extreme IR in the face of obesity. Thus, the rare patient we describe serves as a robust test for an impact of loss of NPC1 function on insulin receptor function in vivo. At first sight, the greater IR in the proband than in her father argues that this predicted exacerbation of IR is being seen in this case. However, this is confounded by the fact that IR is generally expressed more severely in females and is also exacerbated by puberty. Indeed, the fasting insulin levels reported here are very similar to those reported in the father and daughter pair with the closely related Trp1193Leu mutation, and are also in keeping with levels in our cohort of patients with severe IR (Iwanishi et al. 1993). We thus conclude that the effect of loss of NPC1 function on insulin receptor signalling in humans in vivo is likely to be mild at most. Nevertheless, more detailed cross-sectional studies of insulin sensitivity in Niemann Pick disease type $\mathrm{C} 1$ are warranted, and clinicians should be alert to the clinical stigmata of IR, including acanthosis nigricans, and oligomenorrhoea and hyperandrogenism in girls.

Acknowledgements This work was supported by the Wellcome Trust (R.K.S., Intermediate Clinical Fellowship 080952/Z/06/Z; S.O., Programme Grant 078986/Z/06/Z), the UK National Institute for Health Research Cambridge Biomedical Research Centre, and the U. K. Medical Research Council Centre for Obesity and Related Disorders.

\section{References}

Chikh K, Vey S, Simonot C, Vanier MT, Millat G (2004) NiemannPick type C disease: importance of N-glycosylation sites for function and cellular location of the NPC2 protein. Mol Genet Metab 83:220-230

Iwanishi M, Haruta T, Takata Y et al (1993) A mutation (Trp1193-> Leu1193) in the tyrosine kinase domain of the insulin receptor associated with type A syndrome of insulin resistance. Diabetologia 36:414-422

Langeveld M, de Fost M, Aerts JM, Sauerwein HP, Hollak CE (2008a) Overweight, insulin resistance and type II diabetes in type I Gaucher disease patients in relation to enzyme replacement therapy. Blood Cells Mol Dis 40:428-432 
Langeveld M, Ghauharali KJ, Sauerwein HP et al (2008b) Type I Gaucher disease, a glycosphingolipid storage disorder, is associated with insulin resistance. J Clin Endocrinol Metab 93:845-851

Millat G, Bailo N, Molinero S, Rodriguez C, Chikh K, Vanier MT (2005) Niemann-Pick $\mathrm{C}$ disease: use of denaturing high performance liquid chromatography for the detection of NPC1 and NPC2 genetic variations and impact on management of patients and families. Mol Genet Metab 86:220-232

Millat G, Marcais C, Rafi MA et al (1999) Niemann-Pick C1 disease: the I1061T substitution is a frequent mutant allele in patients of Western European descent and correlates with a classic juvenile phenotype. Am J Hum Genet 65:1321-1329

Musso C, Cochran E, Moran SA et al (2004) Clinical course of genetic diseases of the insulin receptor (type A and RabsonMendenhall syndromes): a 30-year prospective. Medicine (Baltimore) 83:209-222

O'Rahilly S (2007) Human obesity and insulin resistance: lessons from experiments of nature. Biochem Soc Trans 35:33-36

Odawara M, Kadowaki T, Yamamoto R et al (1989) Human diabetes associated with a mutation in the tyrosine kinase domain of the insulin receptor. Science 245:66-68
Semple RK, Soos MA, Luan J et al (2006) Elevated plasma adiponectin in humans with genetically defective insulin receptors. J Clin Endocrinol Metab 91:3219-3223

Soos MA, O'Brien RM, Brindle NP et al (1989) Monoclonal antibodies to the insulin receptor mimic metabolic effects of insulin but do not stimulate receptor autophosphorylation in transfected NIH 3 T3 fibroblasts. Proc Natl Acad Sci USA 86:5217-5221

Taylor SI, Cama A, Accili D et al (1992) Mutations in the insulin receptor gene. Endocr Rev 13:566-595

Vainio S, Bykov I, Hermansson M, Jokitalo E, Somerharju P, Ikonen E (2005) Defective insulin receptor activation and altered lipid rafts in Niemann-Pick type $\mathrm{C}$ disease hepatocytes. Biochem $\mathrm{J}$ 391:465-472

Whittaker J, Soos MA, Siddle K (1990) Hybrid insulin receptors. Molecular mechanisms of negative-dominant mutations in receptor-mediated insulin resistance. Diab Care 13:576-581

Yaqoob P (2009) The nutritional significance of lipid rafts. Annu Rev Nutr 29:257-282

Zimmet P, Alberti KG, Shaw J (2001) Global and societal implications of the diabetes epidemic. Nature 414:782-787 